\title{
How does Personality Affect on Job Burnout?
}

\author{
Mohammad Reza Akhavan Anvari, Nader Seyed Kalali, and Aryan Gholipour
}

\begin{abstract}
- this research aims to study the effect of personality traits on job burnout. In the research model, job burnout is dependent variable and independent variables include extraversion, neuroticism, agreeableness, openness to experience and conscientiousness. To clarify the relationships among these variables, structural equation modeling (SEM) was conducted. The data was collected through questionnaire; Participants were 248 workers from the staff of the Tehran Atiyeh Hospital. The results of structural equation model show negative impact of extraversion on job burnout $(-0.08)$, negative impact of agreeableness on job burnout (-0.15), positive impact of conscientiousness on job burnout $(0.02)$, positive impact of neuroticism on job burnout $(0.22)$ and negative impact of openness on job burnout (-0.11).
\end{abstract}

Index Terms-Big Five Model, Job Burnout, Personality and Structural Equation Modeling.

\section{INTRODUCTION}

Burnout term was coined by Herbert Freudenberger in 1974 to describe a special kind of job distress (Freudenberger, 1974). He used the term to describe gradual emotional depletion and missing the motivation and commitment in young volunteer workers with high commitment who work in a clinic (Freudenberger, 1974; Maslach, \& Leiter, 2005). In 1976, Maslach mentioned to the phenomenon of indifference and disrespect of staff toward the organization's clients after long studies on the problems of social services staff (Maslach 1976). Job burnout is a negative emotional reaction to job, created through long attendance in high stress workplaces (Maslach, Schaufeli, \& Leiter, 2001; Maslach, \& Jackson, 1984) In other words, High disharmony between job nature and job holder's nature leads into burnout (Maslach, \& Leiter, 2005).

The aspects of burnout include: (1) emotional exhaustion which means energy discharge and consumption of emotional resources. This dimension can be considered as the cornerstone of job burnout. (2) Depersonalization which separates workers from others and causes pessimism to colleagues, customers and organization. This dimension of the job burnout is prevalent among those staff who regularly communicate to other persons (such as teachers, students, customers, patients) to do their jobs. (3) Diminished personal

Mohammad Reza Akhavan Anvari , Postgraduate, Operations Research, Faculty of Management, University of Tehran *(Corresponding Author) Chamran Highway, Nasr Bridge P.O.Box 14155-6311, Tehran, Iran (email:mrakhavan@ut.ac.ir)

Nader Seyed Kalali , Postgraduate, Operations Research, Faculty of Management, University of Tehran Chamran Highway, Nasr Bridge P.O.Box 14155-6311, Tehran, Iran (email: nader kalali@ut.ac.ir)

Aryan Gholipour , Associate Professor, Faculty of Management, University of Tehran Chamran Highway, Nasr Bridge P.O.Box 14155-6311, Tehran, Iran (email: agholipor@ut.ac.ir) accomplishment by which the person comes to a negative self-assessment (Maslach, \& Leiter, 2005; Maslach, \& Jackson, 1981; Pines, \& Maslach, 1981).

Burnout is an important variable not only because that it is an index to show individuals' weak performance in workplace but also because that it influences on individual's attitudes, their physical and mental health and finally on their behavior (Cordes, \& Dougherty, 1993; Maslach, Schaufeli, \& Leiter, 2001; Lee, \& Ashforth, 1996; Maslach, 2003; Maslach, \& Goldberg, 1998).

\section{LITERATURE REVIEW}

Researches indicate that variables like self-efficacy, self-esteem, locus of control, emotional stability, extraversion, conscientiousness, positive affectivity, negative affectivity, optimism, proactive personality (Bateman, \& Crant, 1993) and hardworking impact highly on burnout (Alarcon, attendance in high stress workplaces (Maslach, Schaufeli, \& Leiter, 2001; Maslach, \& Jackson, 1984) In other words, High disharmony between job nature and job holder's nature leads into burnout (Maslach, \& Leiter, 2005).

The aspects of burnout include: (1) emotional exhaustion which means energy discharge and consumption of emotional resources. This dimension can be considered as the cornerstone of job burnout. (2) Depersonalization which separates workers from others and causes pessimism to colleagues, customers and organization. This dimension of the job burnout is prevalent among those staff who regularly communicate to other persons (such as teachers, students, customers, patients) to do their jobs. (3) Diminished personal accomplishment by which the person comes to a negative self-assessment (Maslach, \& Leiter, 2005; Maslach, \& Jackson, 1981; Pines, \& Maslach, 1981).

Burnout is an important variable not only because that it is an index to show individuals' weak performance in workplace but also because that it influences on individual's attitudes, their physical and mental health and finally on their behavior (Cordes, \& Dougherty, 1993; Maslach, Schaufeli, \& Leiter, 2001; Lee, \& Ashforth, 1996; Maslach, 2003; Maslach, \& Goldberg, 1998).

\section{LITERATURE REVIEW}

Researches indicate that variables like self-efficacy, self-esteem, locus of control, emotional stability, extraversion, conscientiousness, positive affectivity, negative affectivity, optimism, proactive personality (Bateman, \& Crant, 1993) and hardworking impact highly on burnout (Alarcon, said that many findings 
of the research are homogenous to previous researches; however, no relationship was determined between agreeableness/job performance and job burnout (Kim, 2007).

Alarcon et al (2009) mentioned that structured studies on the relationship between personality variables and burnout are rare (Alarcon, Eschleman, \& Bowling, 2009). Since authors confirm the lack of researches in this area, present study addresses to investigate the effect of personality factors (big five personality model) on job burnout. So, the researchers formulate the research hypothesis as follow:

Extraversion has negative and significant impact on job burnout.

Agreeableness has negative and significant impact on job burnout.

Conscientiousness has negative and significant impact on job burnout.

Neuroticism has positive and significant impact on job burnout.

Openness to experience has negative and significant impact on job burnout.

Research conceptual framework is drawn by reviewing the literature and above mentioned hypothesis. Emotional exhaustion, diminished personal accomplishment and depersonalization are the aspects of job burnout and extraversion, agreeableness, conscientiousness, openness and neuroticism are the personality aspects in the Big Five Model. Figure 1 indicates research model.

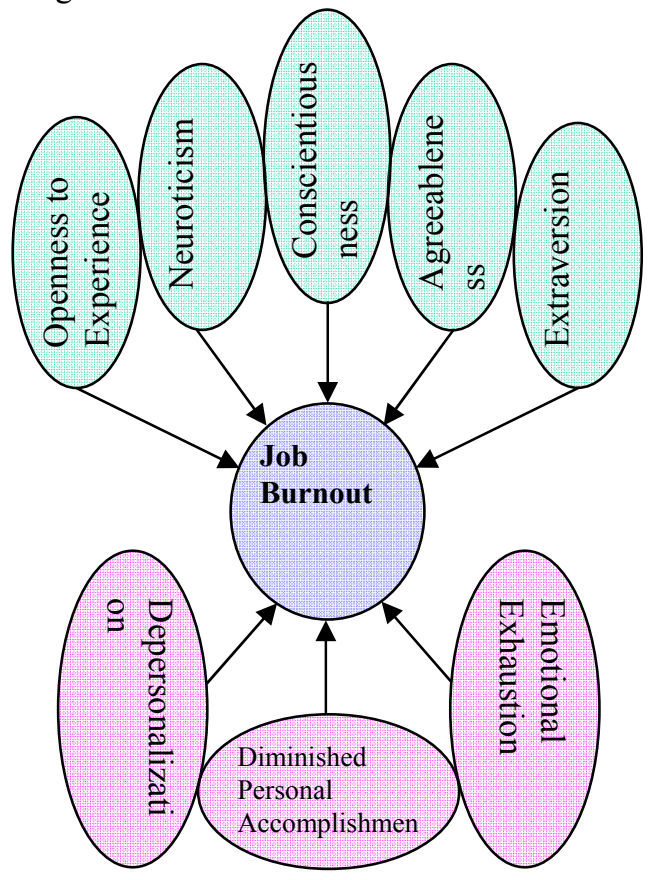

Figure 1. The conceptual framework of this research

\section{Methodology}

The purpose of present research is to determine relationship between the variables of the Big Five Personality Model (extraversion, neuroticism, agreeableness, openness and conscientiousness) and job burnout; so, a structural equation model (SEM) is proposed to analyze this relationship. In research analytical model, job burnout is dependent variable and independent variables include extraversion, neuroticism, agreeableness, openness to experience and conscientiousness. Present research is conducted in winter to spring 2010 in Tehran Atiyeh private hospital.

\section{A. Scale}

There are some scales to measure job burnout of which the most famous ones includes MBI questionnaire. This questionnaire was developed by Maslach in 1980s and then was revised later(Halbesleben, Jonathon, \& Buckley, 2004). A newer scale is Oldenburg job burnout inventory (OLBI) designed to mitigate MBI bias; however, its conceptual foundation is based on MBI. Overall, more evidences are needed to determine OLBI validity and it is not yet possible to replace MBI with OLBI (Halbesleben, Jonathon, \& Buckley, 2004).

In this research, questionnaire is used to measure variables. It is a 66-item questionnaire with Likert's 5-point range and respondents' general (demographical) information. The first 22 items address to study job burnout and it is actually Maslach standard questionnaire (MBI) to measure job burnout. The items in the questionnaire measure three dimensions of job burnout including emotional exhaustion (9 items), diminished personal accomplishment ( 8 items) and depersonalization ( 5 items). In the second part, the 44-item questionnaire of Big Five Personality Standard Model(Costa, \& McCrae, 1989) is providedwhich includes 8 items on extraversion, 9 items on agreeableness, 9 items on conscientiousness, 8 items on neuroticism and 10 items on openness. Cronbach's alpha is utilized to determine the questionnaire's reliability whose rates for three aspects of job burnout namely emotional exhaustion, diminished personal accomplishment and depersonalization are $81.2 \%, 80.5 \%$ and $71.1 \%$ respectively. For other five variables namely extraversion, agreeableness, neuroticism, openness and conscientiousness, these rates are $70.2 \%, 72.6 \%, 75.5 \%$, $82.1 \%$ and $71.7 \%$ respectively which show high reliability of the questionnaire. To determine the validity of various variables in mentioned questionnaire, second-order confirmatory factor analysis was used for exogenous variables and second-order confirmatory factor analysis for endogenous variables.

\section{B. Participants}

Participants were 248 workers from the staff of the Tehran Atiyeh Hospital. Among distributed questionnaires, 14.4\% and $84.7 \%$ of respondents were male and female respectively. Noteworthy, $0.9 \%$ of respondents did not determine their sex. In the meantime, $65.3 \%$ of respondents were married, $33.1 \%$ were single and $1.6 \%$ did not determine their marital status. In terms of education, $21.2 \%$ were under diploma, diploma and associate of arts, $70.3 \%$ were BA, $4.3 \%$ were MA and $4.2 \%$ did not determine their educational level.

\section{FINDINGS}

4.1. Studying the measurement models of endogenous and exogenous variables

a) The findings of burnout second-order confirmatory factor analysis 


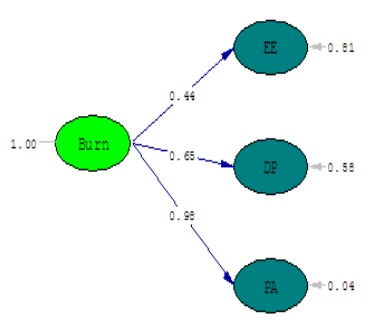

Chi-Squa re $=387.82$, df $=209$, p-value $=0.00000$, RUSEA $=0.077$

Figure 2. Measurement model of burnout

As the results of standard estimation show (figure 2), there is a positive correlation ( 0.44$)$ between burnout and its first aspect namely emotional exhaustion. It means that by one unit increase in emotional exhaustion, one can observe 0.44 units increase in job burnout and the percentage of job burnout explanation (R-Square) via emotional exhaustion would be $(0.442)=0.20$. Regarding the second aspect, there is a positive correlation between burnout and depersonalization (0.65). It means that by one unit increase in depersonalization, one can observe 0.65 units increase in job burnout and the percentage of job burnout explanation via depersonalization would be $(0.652)=0.42$. Finally, there is a positive correlation between burnout and its third aspect namely diminished personal accomplishment (0.98). It means that by one unit increase in diminished personal accomplishment, one can observe 0.98 units increase in job burnout and the percentage of job burnout explanation via diminished personal accomplishment would be $(0.982)=$ 0.96 .

The results of t-value models indicate that all parameters of the model are significant; noteworthy the t-value of emotional exhaustion, depersonalization and diminished personal accomplishment are 3.77, 5.02 and 4.81 respectively. Such significance is due to the fact that the significant $t$-value of all measurement models routes are $>1.96$ or $<-1.96$. Finally, fitness indices indicate proper goodness of job burnout measurement model.

$\frac{\chi^{2}}{d f}=\frac{387.82}{209}=1.85<3 \quad$ Means good fit

\section{RMSEA $=0.077<0.08$ Means good fit}

It should be noted that RMSEA is 0.077 less than 0.08 which shows proper goodness of the model. The amount of Chi-Square is 387.82 and freedom degree is 209 . So, the ratio of Chi-Square to freedom degree is 1.85 which is less than 3. Thus, it is concluded that obtained model has proper and sufficient goodness.

b) The findings of model of the second-order confirmatory factor analysis of the personality (the big five model)

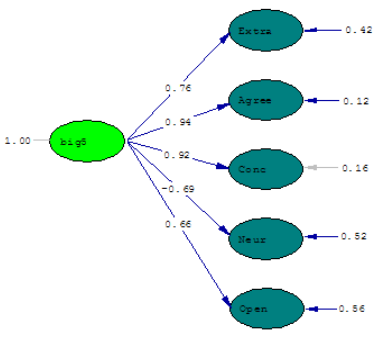

$=1612.55, \mathrm{df}=1019, \mathrm{P}-\mathrm{value}=0.0000$

Figure 3. Measurement model of Big Five
In standard estimation, the correlation coefficients are 0.76 for extraversion, 0.94 for agreeableness, and 0.92 for conscientiousness, -0.69 for neuroticism and 0.66 for openness. Also, the result of t-value of the model is all significant. Noteworthy the t-value for extraversion, agreeableness, neuroticism, openness and conscientiousness are $7.40,3.70,8.64,-4.96$ and 6.74 respectively. Finally, fitness indices indicate proper goodness of job burnout measurement model.

$$
\frac{\chi^{2}}{d f}=\frac{1612.55}{1019}=1.58<3 \quad \text { Means good fit }
$$

RMSEA $=0.049<0.08$ Means good fit

It should be noted that RMSEA is 0.049 and less than 0.08 which shows proper goodness of the model. The amount of Chi-Square is 1612.55 and freedom degree is 1019 . So, the ratio of Chi-Square to freedom degree is 1.58 which is less than 3 . Thus, it is concluded that obtained model has proper and sufficient goodness.

4.2. Evaluating the results of structural equation model

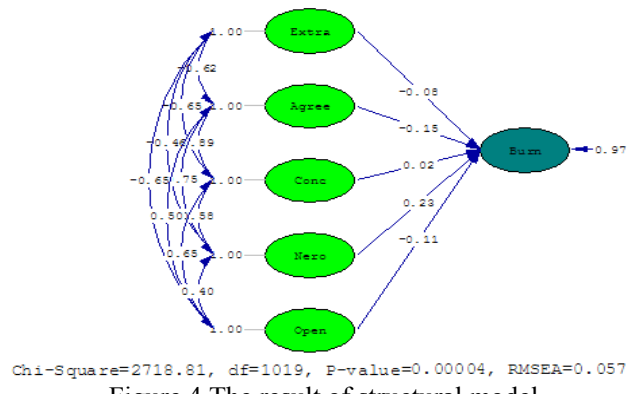

Figure 4.The result of structural model

The results of structural equation model show negative impact of extraversion on job burnout (-0.08), negative impact of agreeableness on job burnout $(-0.15)$, positive impact of conscientiousness on job burnout (0.02), positive impact of neuroticism on job burnout $(0.22)$ and negative impact of openness on job burnout $(-0.11)$. Based on the findings of present research, it is obvious that third statistical hypothesis on the negative and significant impact by conscientiousness on job burnout of mentioned hospital staff is rejected. According to above findings, conscientiousness has a positive impact on job burnout. In the meantime, the results of t-value model indicate that all five casual paths of Big Five model have significant impact on job burnout because that their t-value are $-2.05,-0.89,0.13,3.46$ and -2.14 respectively. Based on the results of t-value model, it is obvious that more extraversion, leads to less job burnout. Such results are true on agreeableness and openness. It means that people with more agreeableness and openness experience less job burnout. More neuroticism,leads to more job burnout. However, the hypothesis of conscientiousness was not supported. The findings indicate that people with higher conscientiousness experience higher job burnout. Therefore, first, second, fourth and fifth hypothesis are supported. The results of fitness indices indicate proper goodness of structural model.

$$
\begin{aligned}
& \frac{\chi^{2}}{d f}=\frac{2718.81}{1019}=2.66<3 \quad \text { Means good fit } \\
& \text { RMSEA }=0.057<0.08 \text { Means good fit }
\end{aligned}
$$


It should be noted that RMSEA is 0.057 less than 0.08

So, it shows proper goodness of the model. The amount of Chi-Square is 2718.81 and freedom degree is 1019 . So, the ratio of Chi-Square to freedom degree is 2.66 which is less than 3. Thus, it is concluded that obtained model has proper and sufficient goodness.

\section{CONCLUSION}

The results of estimation model show negative impact of extraversion on job burnout (-0.08), negative impact of agreeableness on job burnout $(-0.15)$, positive impact of neuroticism on job burnout (0.22) and negative impact of openness on job burnout $(-0.11)$. Thus, the results on extraversion, agreeableness and neuroticism are in line with previous researches (Alarcon et al., 2009; Costa, \& McCrae, 1992; Bowling et al., 2004; Bono, \& Judge, 2003) but in terms of openness, it is in contradictory to previous researches (Alarcon et al., 2009; Costa, \& McCrae, 1992; Piedmont, 1993).

On the other hand, the results of estimation model show the positive impact of conscientiousness on job burnout (0.02). Hence, third statistical assumption on the negative and significant impact by conscientiousness on job burnout of the mentioned hospital staff is rejected. It is concluded that more conscientiousness leads into more burnout; maybe because high conscientiousness do not allow a person to be indifferent toward his job, so he/she is more exposed to job stress and burnout. Therefore, the results indicate that conscientiousness has a positive impact on job burnout. This finding is in contradictory to previous researches (Alarcon et al., 2009; Costa, \& McCrae, 1992).

Here, a question comes to mind: why in contradiction to previous major researches, conscientiousness has a positive correlation with job burnout? For more evaluation, some employees were interviewed and it was surprisingly concluded that in surveyed organization, conscientious people have not properly awarded despite of their more efforts. Maslach and Leiter (2005) identified two groups of factors which dominate the person before burnout. The first group is called situational predictors consist of six antecedents: (1) workload, (2) control, (3) award, (4) social interactions, (5) fairness and (6) values. The second group or individual antecedents include such factors as age, gender, marital status and experience. One can guess that unfair award distribution mitigates the relationship between conscientiousness and job burnout. Researchers can examine this assumption in future studies. So, it is concluded that extravert individuals are less suffer job burnout, Agreeable and open persons also experience less job burnout and neurotic and conscientious individuals have higher job burnout (Maslach, \& Leiter, 2005).

In terms of impact extent, among personality variables, neuroticism has the highest impact (0.22) andconscientiousnesshas the lowest impact (0.02) on job burnout. By using these findings, managers can prevent the intensification of job burnout through being aware of their employees' personality traits. As mentioned, the results of previous researches show that factors like workload, control, award, social interactions, fairness and values are correlated with job burnout. By enforcing happiness creating factors and job burnout mitigating factors, managers can control job burnout and prevent its serious consequences which hurt employees mentally and physically. In the meantime, interventional plans are useful in this regard. Used interventional plans in organizations to mitigate job burnout involve a wide range. Such plans can have individual and organizational orientation or a combination of both. One can, points out individual interventional plans such as job competency improvement, individual confronting skills enhancement, social support or relaxation exercises. There are various organizational interventional plans like reengineering, job control increase and involving staff in decision-making. Creating and enhancing job advising plans in organizations are among the most effective mechanisms to mitigate job burnout (Gorter et al., 2001).

\section{REFERENCES}

[1] Alarcon, G., Eschleman, K. J., \& Bowling, N. A. (2009). Relationship between Personality Variables and Burnout: A Meta-Analysis. Work \& Stress, Vol. 23, No. 3, July-September, 244-263.

[2] Allen, J., Mellor, D. (2002). Work context, personal control, and burnout among nurses. Western Journal of Nursing Research 24, 905-917.

[3] Bateman, T. S., \& Crant, J. M. (1993). The proactive component of organizational behavior: A measure and correlates. Journal of Organizational Behavior, 14(2), 103_118.

[4] Bettina, F. P. (2006). Burnout, role conflict, job satisfaction and psychosocial health among Hungarian health care staff: A questionnaire survey. International Journal of Nursing Studies, Volume 43, Issue 3, March 2006, Pages 311-318.

[5] Bono, J. E., \& Judge, T. A. (2003). Core self-evaluations: A review of the trait and its role in job satisfaction and job performance. European Journal of Personality, 17, S5_S18.

[6] Bouman, A. H., Te Brake, H., \& Hoogstraten, J. (2002). Significant effects due to rephrasing the Maslach Burnout Inventory's personal accomplishment items. Psychological Reports, 91: 825-826.

[7] Bowling, N. A., Beehr, T. A., Johnson, A. L., Semmer, N. K., Hendricks, E. A., \& Webster, H. (2004). Explaining the potential antecedents of workplace social support: Reciprocity or attraction? Journal of Occupational Health Psychology, 9, 339_350.

[8] Burke, M. J., Brief, A. P., \& George, J. M. (1993). The role of negative affectivity in understanding relations between self-reports of stressors and strains: a comment on the applied psychology literature. Journal of Applied Psychology 78, 402-412.

[9] Chen, P. Y., \& Spector, P. E. (1991). Negative affectivity as the underlying cause of correlations between stressors and strains. Journal of Applied Psychology 76, 398-400.

[10] Compact Oxford English Dictionary of Current English, oxford dictionaries, 2008.

[11] Conrad, K. M., Conrad, K. J., \& Parker, J. E. (1985).Jobsatisfaction amongoccupationalhealthnurses. JournalofCommunityHealthNursing2,161-173.

[12] Cordes, C. L., \& Dougherty, T. W. (1993). A review and an integration of research on job burnout. Academy of Management Review, 18, 621-656.

[13] Cordes, C. L., Dougherty, T. W., \& Blum, M. (1997), Patterns of burnout among managers and professionals: a comparison of models, Journal of Organizational Behaviour, Vol. 18 No. 6, pp. 685-701.

[14] Costa, P. T. Jr., \& McCrae, R. R. (1989). NEO PI/FFI manual supplement. Odessa, FL: Psychological Assessment Resources.

[15] Costa, P. T. Jr., \& McCrae, R. R. (1992). Normal personality assessment in clinical practice: The NEO Personality Inventory. Psychological Assessment, 4, 5_13.

[16] Day, D. V., \& Bedeian, A. G. (1995). Personality similarity and work-related outcomes among African-American nursing personnel: a test of the supplementary model of person-environment congruence. Journal of Vocational Behavior 46, 55-70.

[17] De Vries, J., \& Van Heck, G. L. (2002). Fatigue: relationships with basic personality and temperament dimensions. Personality and Individual Differences 33, 1311-1324. 
[18] Decker, P. J., \& Borgen, F. H. (1993). Dimensions of work appraisal: stress, strain, coping, job satisfaction, and negative affectivity. Journal of Counseling Psychology 40, 470-478.

[19] Drake, B., \& Yadama, G. N. (1996). A structural equation model of burnout and job exit among child protective services workers. Social Work Research, 20: 179-187.

[20] Elliott, T. R., Chartrand, J. M., \& Harkins, S. W. (1994). Negative affectivity, emotional distress, and the cognitive appraisal of occupational stress. Journal of Vocational Behavior 45, 185-201.

[21] Freudenberger, H. J. (1974), Staff burnout , Journal of Social Issues, Vol. 30, pp. 159-65.

[22] Ganster, D. C. (1986). Type A behavior and occupational stress. Journal of Organizational Behavior Management 8, 61-84.

[23] Geurts, S., Schaufeli, W., \& De Jonge, J. (1998). Burnout and intention to leave among mental health-care professionals: A social psychological approach. Journal of Social and Clinical Psychology, 17: 341-362.

[24] Goddard, R., Patton, W., \& Creed, P. (2004). The importance and place of neuroticism in predicting burnout in employment service case managers. Journal of Applied Social Psychology 34 (2), 282-296.

[25] Gorter, R. C., Eijkman, M. A. J., \& Hoogstraten, J. (2001). Acareercounselingprogramfordentists:effectsonburnout.Patien tEducCouns ; 43:23-30.

[26] Gosling, S. D., Rentfrow, P. J., \& Swann, W. B. Jr. (2003). A very brief Measure of the Big-Five personality domains. Journal of Research in Personality, 37, 504-528.

[27] Gray, R. A., Niehoff, B. P., \& Miller, J. L. (2000). The effect of job characteristics on student Employee job satisfaction an dintenttoturn over in college and university Food service. Journal of theNational Association of College \& University Food-services 21, 14-29.

[28] Halbesleben, J. R. B., \& Buckley M. R. (2004). Burnout in organizational life, journal of management, 2004 30(6) 859-879.

[29] Herzberg, F., \& Mausner, B. TheMotivationtoWork,Seconded.Wiley,NewYork.

[30] Iverson, R. D., Olekalns, M., \& Erwin, P. J. (1998). Affectivity, organizational stressors, and absenteeism: a causal model of burnout and its consequences. Journal of Vocational Behavior 52, 1-23.

[31] Judge, T. A., Erez, A., Bono, J. E., \& Thoresen, C. J. (2003). The core self evaluations scale: Development of a measurement. Personnel Psychology, 56, 303331.

[32] Kahn, J. H., Schneider, K. T., Jenkins-Henkelman, T. M., \& Moyle, L. L. (2006). Emotional social support and job burnout among high-school teachers: is it all due to dispositional affectivity? Journal of Organizational Behavior 27, 793-807.

[33] Kim, H. J., Shin, K. H., \& Umbreit, W. T. (2007). Hotel job burnout: The role of personality characteristics. International Journal of Hospitality Management, 26, 421434.

[34] Kirmeyer, S. L. (1988). Coping with competing demands: interruption and the Type A pattern. Journal of Applied Psychology 73, 621-629.

[35] Koeske, G., \& Koeske, R. (1993). A preliminary test of the stress-strain-outcome model for reconceptualizing the burnout phenomenon. Social Service Research, 17: 107-135.

[36] Lee, C., \& Ashforth, B. E. (1996). A meta-analytic examination of the correlates of three dimensions of job burnout. Journal of Applied Psychology, 81, 123_133.

[37] Maslach, C. (2003). Job burnout: New directions in research and intervention. Current Directions in Psychological Science, 12, $189 \_192$.

[38] Maslach, C., \& Jackson, S. E. (1981). The measurement of experienced burnout, Journal of Occupational Behavior, Vol. 2, pp. 99-113.

[39] Maslach, C., \& Leiter, M. P. (2005). Stress and burnout: the critical research, in Cooper, C.L. (Ed.), Handbook of Stress Medicine and Health, CRC Press, Lancaster, pp. 155-72.

[40] Maslach, C., \& Goldberg, J. (1998). Prevention of burnout: New perspectives. Applied \& Preventive Psychology, 7, $63 \_74$.

[41] Maslach, C., \& Jackson, S. E. (1984). Burnout in organizational settings. Applied Social Psychology Annual, 5, 133_153.

[42] Maslach, C. (1976). Burned-out. Human Behav. 5, $\overline{16}-22$.

[43] Maslach, C. (1978). The client role in staff burnout. Journal ofSocial Issues 34, 11-24.

[44] Maslach, C., \& Pines, A. (1977). The burn-out syndrome in thedaycare setting. Child Care Quarterly 6 (2), 100-113.
[45] Maslach, C., Schaufeli, W. B., \& Leiter, M. P. (2001). Job burnout. In S. T. Fiske, D. L. Schacter \& C. Zahn-Waxler (Eds.), Annual Review of Psychology, 52, 397-422.

[46] Mathieu, J. E., \& Zajac, D. (1990). A review and meta-analysis of the antecedents, correlates, and consequences of organizational commitment. Psychological Bulletin, 108, 171-194

[47] Mills, L. B., \& Huebner, E. S. (1998). A prospective study of personality characteristics, occupational stressors, and burnout among school psychology practitioners. Journal of School Psychology 36, 103-120.

[48] Mobley, W. H., Horner, S. O., \& Hollingsworth, A. T. (1978).AnevaluationofprecursorsofHospitalemployeeturnover. Journal of Applied Psychology 63,408-414

[49] Moore, J. E. (2000). Why is this happening? A causal attribution approach to work exhaustion consequences. Acad. Manage. Rev. 25, 335-349.

[50] Mughal, S., Walsh, J., \& Wilding, J. (1996). Stress and work performance: the role of trait anxiety. Personality and Individual Differences 20, 685-691.

[51] Ng, T. W. H., Sorensen, K. L., \& Eby, L. T. (2006). Locus of control at work: A meta-analysis. Journal of Organizational Behavior, 27, 10571087.

[52] Noor, N. M. (1997). Work and family roles in relation to women's well-being: the role of negative affectivity. Personality and Individual Differences 23, 487-499.

[53] Piedmont, R. L. (1993). A longitudinal analysis of burnout in the health care setting: The role of personal dispositions. Journal of Personality Assessment, 61, 457_473.

[54] Pines, A. M., \& Maslach, C. (1981). Burnout: from tedium to personal growth. New York Macmillan. Psychology, Vol 72, pp. 269-274.

[55] Price, J. L. (2001).Reflectionsonthedeterminantsofvoluntaryturnover. InternationalJournalofManpower22 (7),600-624.

[56] Rocca, A. D., \& Kostanski, M. (2001) Burnout and job satisfaction amongst Victorian secondary school teachers: a comparative look at contract and permanent employment. Paper Delivered at the ATEA Conference, Teacher education: change of heart, mind and action, 24-26September, Melbourne, Victoria.

[57] Rusbult, C. E., \& Farrel, D. (1983). A longitudinal test of the investment model: the impact on job satisfaction, job commitment, and turnover of variations in rewards, costs, alternatives, and investments. Journal of applied psychology, 68, 429-438.

[58] Rush, M. C., Schoel, W. A., \& Barnard, S. M. (1995). Psychological resiliency in the public sector: "hardness" and pressure for change. Journal of Vocational Behavior 46, 17-39.

[59] Schaufeli, W. B., \& Enzmann, D. (1998). the burnout companion to study and practice: a critical analysis. taylor\&francis, London.

[60] Schaufeli, W. B., Leiter, P. M., \& Maslach, C. (2009). Burnout: 35 years of Research and practice, career development international, Vol.14, No.3, pp. 204-220.

[61] Schwab, R. L., \& Iwanicki, E. F. (1982). Who are our burned out teachers? Educational Research Quarterly, 7(2), 5-16.

[62] Singh, J., Goolsby, J. R., \& Rhoads, G. K. (1994). Behavioral and psychological consequences of boundary spanning burnout for customer service representatives. Journal of Marketing Research, 31: 558-569.

[63] Spector, P. E., \& O'Connell, B. J. (1994). The contribution of personality traits, negative affectivity, locus of control and Type A to the subsequent reports of job stressors and job strains. Journal of Occupational and Organizational Psychology 67, 112.

[64] Steel, R. P., \& Ovalle, N. K. (1984). Areviewandmeta-analysis of research on the Relationship between behavior alintentions and employee turnover. Journal of Applied Psychology 69 (4), 673-686.

[65] The measurement equivalence of Big-Five factor markers for persons with different levels of education, B Rammstedt, LR Goldberg, I Borg, Journal of Research in Personality, 44 (2010) 53-61.

[66] Thoresen, C. J., Kaplan, S. A., Barsky, A., Warren, C. R., \& deChermont, K. (2003). The affective underpinnings of job perceptions and attitudes: A meta-analytic review and integration. Psychological Bulletin, 129, 914945.

[67] Wiener, Y. (1982). Commitment in organizations: A normative view. Academy of management review, 7,418-428

[68] Zellars, K. L., Perrewe, P. L., \& Hochwarter, W. A. (2000). Burnout in health care: the role of the five factors of personality. Journal of Applied Social Psychology 30, 1570-1598. 